\title{
Safety and Efficacy of Neuroform for Treatment of Intracranial Aneurysms: A Prospective, Consecutive, French Multicentric Study
}

J.C. Gentric, A. Biondi, M. Piotin, C. Mounayer, K. Lobotesis, A. Bonafé, V. Costalat, for the French SENAT Investigators

\begin{abstract}
BACKGROUND AND PURPOSE: Endovascular embolization of wide-neck intracranial aneurysms can be technically challenging, especially when the anatomy is complex. Stent reconstruction of the parent artery is commonly used to treat wide-neck and bifurcated aneurysms. The main objective of this study was to investigate the periprocedural and midterm morbidity and mortality results of this procedure.
\end{abstract}

MATERIALS AND METHODS: SENAT is a consecutive, prospective, multicentric study. Patients with unruptured cerebral aneurysms who underwent endovascular treatment with the Neuroform stent system were recruited and recorded. Technical outcomes and complications were also assessed. The midterm anatomic results were re-evaluated at 12-18 months.

RESULTS: A total of 113 stents were used to treat the 107 aneurysms in 107 patients. The mean width of the aneurysm sac was $6.2 \mathrm{~mm}$, and the mean diameter of aneurysm neck was $4.5 \mathrm{~mm}$. The complete occlusion rate postprocedure was $66.4 \%$. The rate of progressive occlusion at $12-18$ months was $14 \%$, and the rate of recurrence was $9.7 \%$. The rate of subsequent treatment was $4 \%$. The thromboembolic rate in the periprocedural period was $3.7 \%$, and the rate of delayed TE events was $3 \%$. Overall, the mortality rate at $12-18$ months was $1 \%$, and the permanent morbidity rate was $1 \%$.

CONCLUSIONS: Stent-assisted coiling with the Neuroform stent system provides a high level of occlusion with low rates of subsequent treatment despite a predominant population of patients with wide-neck aneurysms. Morbidity and thromboembolic rates were comparable to studies investigating stand-alone coiling.

ABBREVIATIONS: $\mathrm{FU}=$ follow-up; $\mathrm{mRS}=$ modified Rankin Scale; $\mathrm{SAC}=$ stent-assisted coiling; $\mathrm{TE}=$ thromboembolic; $\mathrm{UIA}=$ unruptured intracranial aneurysm; $V E R=$ volume embolization ratio

$\mathbf{E}^{\mathrm{nd}} \mathrm{d}$ ndovascular embolization of wide-neck intracranial aneurysms is technically challenging, especially when the anatomy is complex. Numerous devices have been developed to assist in the treatment of more complex aneurysms. Despite significant im-

Received June 7, 2012; accepted after revision August 13.

From CHU Cavale Blanche, Neuroradiology, (J.C.G.) Brest, France; Department of Neuroradiology and Vascular Imaging (A. Biondi), Besançon, France; Fondation Ophtalmologique Adolphe de Rothschild, Neuroradiology (M.P.), Paris, France; CHU Dupuytren, Neuroradiology (C.M.), Limoges, France; Imaging Department (K.L.), Imperial College Healthcare NHS Trust, London, UK; and CHU Montpellier, Neuroradiology (A. Bonafé, V.C.), Montpellier, France.

Grant support: Boston Scientific/Stryker, Fremont, California.

Principal Investigators of the SENAT Study: Prof. Alessandra Biondi and Prof. Alain Bonafé

A. Biondi, A. Bonafé, and V.C. contributed to the design of the study. J.C.G., A.B., K.L., and V.C. performed analysis and interpretation of data. J.C.G., K.L., A. Bonafé, and V.C. drafted or revised the article for important intellectual content. A. Biondi, A. Bonafé, M.P., and C.M. enrolled most of the patients in this study.

Please address correspondence to Vincent Costalat, MD, PhD, CHU Montpellier, Neuroradiology, Hopital Gui de Chauliac, Av Augustin Fliche, 34295 Montpellier Cedex 5, France; E-mail: vincentcost@hotmail.fr

http://dx.doi.org/10.3174/ajnr.A3379 provements in coil and balloon design, ${ }^{1}$ stent-assisted embolization of wide-neck and bifurcated aneurysms is widely used. ${ }^{2}$ The self-expanding Neuroform stent system (Stryker Neurovascular, Fremont, California) has been available since 2005. This opencell mesh stent has a high degree of elasticity and deformability and was designed for the treatment of complex cerebral aneurysms. After approval by the US Food and Drug Administration, many studies have been reported investigating the safety of Neuroform-assisted coiling, and the technique is still under evaluation. ${ }^{3-13}$

SENAT is the first consecutive, prospective, multicentric study specifically designed to assess the Neuroform stent system in stent-assisted coiling. Patients with UIA who underwent endovascular treatment with the stent were recruited in 10 national institutions in Europe and their results recorded by means of a central data base. The main objective was to study the periprocedural and midterm morbidity and mortality rates. Technical results and complications were also reported. Second, the midterm angiographic results were re-evaluated at 12-18 months. 
Table 1: Modified Rankin Scale scores preprocedure for 107 unruptured aneurysms

\begin{tabular}{lcc}
\multicolumn{1}{c}{ Modified Rankin Score (mRS) } & $n$ & $\%$ \\
\hline $\begin{array}{l}\text { 0: No symptoms at all } \\
\text { 1: No significant disability despite symptoms; able } \\
\quad \text { to carry out all usual duties and activities }\end{array}$ & 84 & 78.5 \\
2: Slight disability; unable to carry out all previous & 14 & 13.1 \\
$\quad \begin{array}{l}\text { activities but able to look after own affairs without assistance } \\
\text { 3: Moderate disability; requiring some help but able } \\
\text { to walk without assistance }\end{array}$ & 4 & 3.7 \\
$\begin{array}{l}\text { 4: Moderately severe disability; unable to walk without } \\
\text { assistance and unable to attend to own bodily needs without assistance }\end{array}$ & 2 & 1.9 \\
\hline Note:-The mRS ranges from 0-4. & 3 & 2.8 \\
\hline
\end{tabular}

Note:-The mRS ranges from $0-4$.

Table 2: Aneurysm topography

\begin{tabular}{lrc}
\hline \multicolumn{1}{c}{ Localization } & $\boldsymbol{n}$ & $\%$ \\
\hline Internal carotid artery (cavernous segment) & 6 & 5.6 \\
Internal carotid artery (ophthalmic segment) & 30 & 28 \\
Internal carotid artery (communicating segment) & 3 & 2.8 \\
Anterior choroidal artery & 3 & 2.8 \\
Middle cerebral artery & 28 & 26.2 \\
Pericallosal artery & 2 & 1.9 \\
Anterior communicating artery & 8 & 7.5 \\
Posterior communicating artery & 16 & 15 \\
Posterior cerebral artery & 1 & 0.9 \\
Superior cerebellar artery & 1 & 0.9 \\
Basilar tip & 9 & 8.4 \\
Total & 107 & 100 \\
\hline
\end{tabular}

\section{MATERIALS AND METHODS Study Design}

An institutional review board approval was obtained in each investigating center. Between January 2008 and April 2010, a total of 107 patients harboring an UIA were included. Patients were older than 18 years and gave their consent for the study. A central online data base was used to collect data. Exclusion factors included dissecting and fusiform aneurysms, multiple aneurysms, and aneurysms associated with an AVM. The use of another stent other than the Neuroform system was also defined as an exclusion criterion. Patients lost to follow-up; pregnant patients; and patients with contraindications to heparin, clopidogrel, or aspirin were also excluded.

\section{Endovascular Therapy Procedures}

Each procedure was performed via a femoral approach with the patients under general anesthesia. All patients received an initial heparin bolus (70-100 UI/kg) followed by continuous infusion. Antiplatelet drugs were administrated according to each institution's protocol and under the direction and management of each participating investigator. The aneurysm and the parent vessel were investigated via $3 \mathrm{D}$ rotational angiography before stent placement.

All patients were treated with the Neuroform system only. Stents were chosen allowing for 5-mm coverage on either side of the aneurysm neck. A variety of coiling techniques were used. The first technique was to jail the microcatheter (jailing) between the stent and the vessel wall, the second technique involved inserting the microcatheter through the struts of the stent, and the third technique entailed placing the stent after coiling.

\section{Clinical Evaluation}

Clinical evaluations were performed before and after treatment, at hospital discharge, at 1 month after treatment, and at 12-18 month follow-up. The neurologic status and the mRS were compared with initial clinical status. Morbidity was defined as any worsening in comparison with the initial mRS.

\section{Anatomic Evaluation}

At the end of the procedure, working projections were used to classify the occlusion as complete occlusion, residual neck, or residual aneurysm according to the modified Montreal scale. ${ }^{14}$ At $12-18$ months, the occlusion was compared with postprocedural results. Progressive occlusion was defined as any perceptible improvement from the initial results. Recurrence was classified as minor or major. Major recurrence was defined as requirement of subsequent treatment.

\section{Complications}

An adjudication committee (A. Biondi, A. Bonafé) reviewed adverse events. Complications were classified according to the time of the event and clinical consequences.

\section{Statistical Analysis}

Means, medians, and ranges were given for continuous variables. Morbidity and mortality rates were calculated from the date of the endovascular treatment.

\section{RESULTS}

\section{Patients and Clinical Presentation}

Initially, 123 patients were included, from which 16 patients were later withdrawn from the data base: 8 because of protocol deviations and 8 because of stent placement in the acute phase of SAH. Among the 107 patients kept for analysis, 74 were women and 33 were men (mean age, 51.83 years; median, 52 years; age range, 23-77 years). Eighty-four (78.5\%) presented with an initial mRS score of 0 (Table 1).

\section{Aneurysm Characteristics}

Among the 107 aneurysms, 91.6\% $(n=98)$ were wide-neck with a dome-to-neck ratio of $<2$. Mean aneurysm width was $6.21 \mathrm{~mm}$ (median, $5.5 \mathrm{~mm}$; range, $2.5-20 \mathrm{~mm}$ ), 52.3\% of the aneurysms were $<6 \mathrm{~mm}(n=56), 38.3 \%$ ranged between 6 and $9.9 \mathrm{~mm}(n=$ 41 ), and $9.4 \%$ ranged between 10 and $24.9 \mathrm{~mm}(n=10)$. Mean height of the sac was $5.77 \mathrm{~mm}$ (median, $5 \mathrm{~mm}$; range, 1.9-16 $\mathrm{mm}$ ). Mean diameter of the aneurysm neck was $4.55 \mathrm{~mm}$ (median, $4 \mathrm{~mm}$; range, 2-15 $\mathrm{mm}$ ).

The most common locations were the paraophthalmic segment of the internal carotid artery $(28 \%)$, the middle cerebral artery (26.2\%), and the posterior communicating artery (15\%). Aneurysm locations are summarized in Table 2.

\section{Technical Results of the Procedure}

A total of 113 Neuroform stents were used to treat 107 aneurysms in 107 patients. A total of 111 stents were implanted; 2 stents failed to be deployed in the parent artery. There were 101 aneurysms 
Table 3: Summary of the antiplatelet regimens for 107 patients

\begin{tabular}{lccc}
\hline Antiplatelet & Preprocedure & Periprocedure & Postprocedure \\
\hline Clopidogrel & & & \\
No. patients (\%) & $98(91.6)$ & $29(27.1)$ & $102(95.3)$ \\
Mean dose (mg) & 204 & 159 & 76 \\
Median (mg) & 225 & 75 & 75 \\
Range (mg) & $75-600$ & $75-600$ & $75-150$ \\
Aspirin & & & \\
No. patients (\%) & $45(42.1)$ & $65(60.7)$ & $97(90.7)$ \\
Mean dose (mg) & 158 & 245 & 159 \\
Median (mg) & 160 & 250 & 160 \\
Range (mg) & $75-250$ & $150-500$ & $75-250$ \\
\hline
\end{tabular}

Table 4: Postprocedural anatomic results

\begin{tabular}{lcc}
\hline Aneurysm Anatomy & $\boldsymbol{n}$ & $\%$ \\
\hline Complete occlusion & 71 & 66.4 \\
Residual neck & 22 & 20.6 \\
Residual aneurysm & 14 & 13.1 \\
Total & 107 & 100 \\
\hline
\end{tabular}

that were treated with 1 stent, and 2 stents were used to treat a single aneurysm in 6 cases. A total of 3 stents were placed for bailout/salvage purposes: 1 because of coil protrusion into the parent vessel, 1 to restore flow in an occluded vessel, and 1 after dissection of the parent artery after balloon remodeling.

Six technical failures $(5.6 \%)$ were reported. Two cases of stent delivery failure were followed by successful implantation on a second attempt. Stent misplacement occurred twice and was managed in 1 instance by placement of a second stent (telescopic stent placement). Dislodgment of the stent into the aneurysmal sac resulting from inappropriate sizing was also reported once. In the last case of stent delivery failure, details were not available.

\section{Antiplatelet Regimen}

No antiplatelet medication protocol was specified in SENAT, as antiplatelet drugs were prescribed and administered at the discretion of the patient management team. Clopidogrel and aspirin regimens-before, during and after procedures-are summarized in Table 3.

During the procedure, a loading dose of clopidogrel was administrated via a nasogastric tube in 29 patients and intravenous aspirin in 65 patients. After the treatment, dual antiplatelet medication was prescribed for a minimum period of 2 months in $90 \%$ of the patients. The mean duration was 13.6 weeks for clopidogrel (median, 12 weeks; range, 4-52 weeks) and 32.7 weeks for aspirin (median, 24 weeks; range, 6-100 weeks).

\section{Anatomic Postprocedure Results}

Acute anatomic results are summarized in Table 4.

\section{Periprocedural Complications}

The overall periprocedural rate of adverse events was 12.1\% (13/ 107) (Figure). During the periprocedural period, 4 (3.7\%) TE adverse events occurred: 1 in-stent thrombosis that remained asymptomatic after administration of abciximab (Reopro); and 1 TE complication that occurred before stent placement, which resulted in permanent disability (mRS score, 1 ) at hospital discharge. The other 2 TE events led to transient neurologic mani- festations before hospital discharge. Regarding hemorrhagic complications, 1 large retroperitoneal hematoma was responsible for a secondary hemodynamic stroke (mRS score, 1 at discharge), and 1 perforation of the aneurysm sac occurred during first coil deployment without clinical consequence. Also, 5 limited groin hematomas were reported. In sum, the periprocedural morbidity rate was $1.9 \%$ (2/107).

\section{Clinical Follow-Up at 1 Month}

All 107 patients completed the 1-month clinical evaluation. The neurologic status was unchanged in 103 patients and was improved in 4 patients. The 2 patients in whom symptomatic periprocedural complications developed had made a complete recovery (mRS score, 0 ), and 2 patients without periprocedural complications clinically improved after aneurysm occlusion (mRS score, 0 ).

Transient neurologic manifestations after treatment of a large carotid aneurysm, most likely secondary to brain stem compression, led to urgent subsequent treatment with internal carotid occlusion. Within the first month, no additional morbidity related to the stent or coils was reported (0/107).

\section{Delayed Complications at 12-18 Months}

During the follow-up period of 12-18 months, 100 patients were available for evaluation. Neurologic status was unchanged in 94 patients, improved in 4 patients, and deteriorated in 1 patient; 1 patient had died. The permanent $12-18$-month morbidity rate was $1 \%(1 / 100)$, and the mortality rate was $1 \%(1 / 100)$ from an unrelated cause (pneumonia).

Delayed complications were reported in 5 patients (5\%). An ICA asymptomatic dissection was observed on the 12-18-month angiogram, and 3 delayed TE adverse events (3\%) were reported. In the first patient, an ischemic lesion was observed 7 months after embolization of an anterior cerebral artery aneurysm, which coincided with the discontinuation of clopidogrel therapy. This patient was rated as having an mRS score of 1 at the 12-18-month follow-up. In the second patient, a left ICA transient ischemic attack occurred 13 months after the initial procedure. In the third patient, a transient amaurosis was reported 1 year after the procedure. No aneurysm bleeding was observed during the follow-up period.

\section{Anatomic Results at 12-18 Months}

Anatomic evaluation was available for 93 patients: 70 were investigated by DSA, 21 by means of MRA, and 2 by CTA. Progressive occlusion occurred in 13 patients (14\%), and aneurysm recurrence was observed in 9 patients $(9.7 \%)$ (Table 5). Complete occlusion was obtained in $69(74.2 \%)$ of 93 patients at $12-18$ months compared with $63(67.7 \%)$ of 93 patients in the postoperative evaluation. Residual neck recurrence decreased from 17 of 93 patients $(18.3 \%)$ to 11 patients $(11.8 \%)$.

\section{Subsequent Treatment of Aneurysms}

Among the 13 residual aneurysms, 4 were re-treated by additional coiling before the end of the first year of follow-up. The overall rate of subsequent treatment was 4.3\% (4/93). 


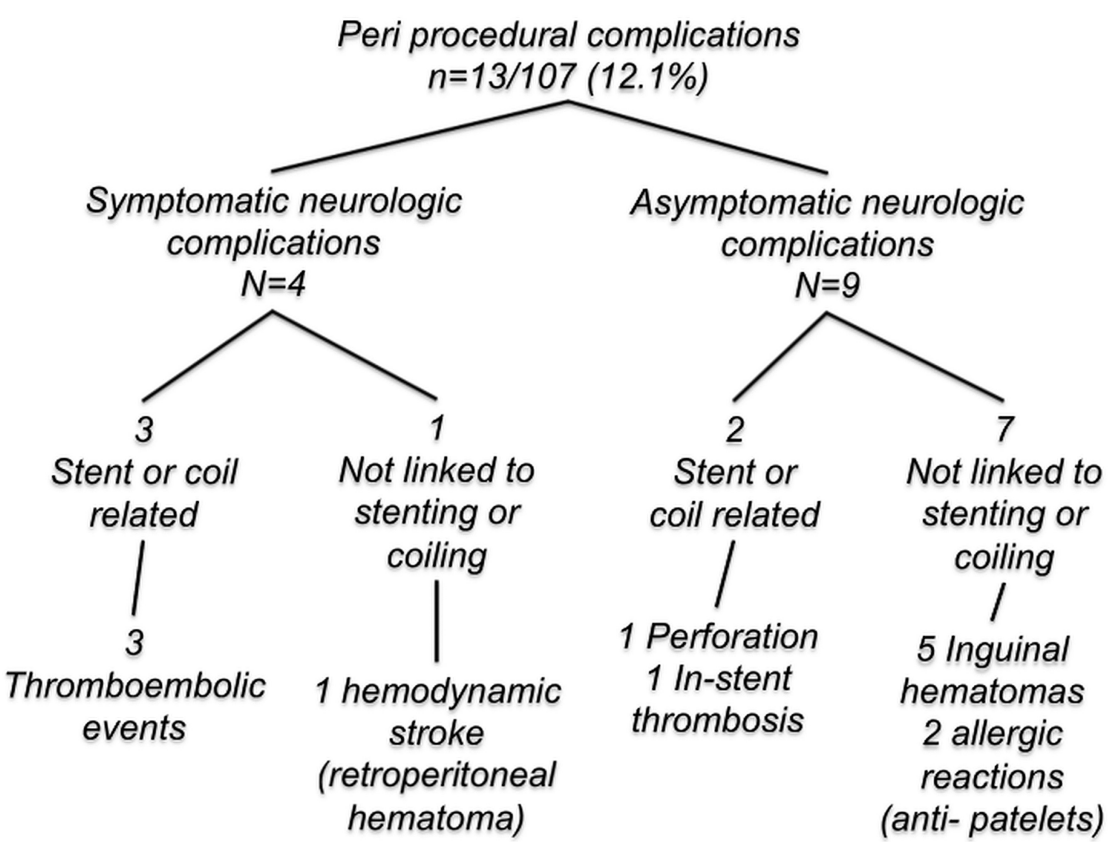

Flow chart. Periprocedural complications.

Table 5: Cross-table results of postprocedural occlusion and occlusion at 12-18 months

\begin{tabular}{lcccc}
\hline & \multicolumn{3}{c}{$\begin{array}{c}\text { Angiographic Results } \\
\text { Follow-Up (12-18 months) }\end{array}$} & \\
\cline { 2 - 4 } & $\begin{array}{c}\text { Complete } \\
\text { Occlusion }\end{array}$ & $\begin{array}{c}\text { Residual } \\
\text { Neck }\end{array}$ & $\begin{array}{c}\text { Residual } \\
\text { Aneurysm }\end{array}$ & Total \\
\hline Postoperative angiographic results & & & & \\
Complete occlusion & $58^{\mathrm{a}}$ & $3^{\mathrm{c}}$ & $2^{\mathrm{c}}$ & 63 \\
Residual neck & $7^{\mathrm{b}}$ & $6^{\mathrm{a}}$ & $4^{\mathrm{c}}$ & 17 \\
Residual aneurysm & $4^{\mathrm{b}}$ & $2^{\mathrm{b}}$ & $7^{\mathrm{a}}$ & 13 \\
Total & 69 & 11 & 13 & 93 \\
\hline
\end{tabular}

a Stable occlusion.

${ }^{\mathrm{b}}$ Progressive occlusion.

${ }^{\mathrm{C}}$ Aneurysm recurrence.

\section{DISCUSSION}

SENAT is the first prospective, consecutive, multicentric study of the Neuroform stent. As in previous monocentric studies ${ }^{3-13}$, this study underlines a high technical success rate and suggests a lower aneurysm recurrence rate at midterm follow-up. Nevertheless, slight discrepancies were observed and are discussed below.

Our study confirms the high rate of successful deployment of the Neuroform stent at first attempt (94.4\% [101/107]). Several studies report a high rate of primary technical success ranging from $66 \%-100 \%$, whereas difficulties in stent placement are reported in the literature to be between $0 \%$ and $34 \% .^{3-8,11-13,15-18}$ In SENAT, the observed failure rate is reasonably low (5.6\% [6/ 107]). This wide range of success may be explained by the ongoing development of the Neuroform device between 2003 and 2007 and the variable learning curve between interventionalist teams during this period.

It is interesting to note that the mean size of the aneurysms in SENAT $(6.21 \mathrm{~mm})$ is lower than in previous studies $3,6-8,11,12$ (mean range, $8-10 \mathrm{~mm}$ ). This trend most likely reflects more common use of this technique, which was initially reserved for wide-neck aneurysms. Compared with conventional coiling, ${ }^{14,19,20}$ stent-assisted coiling ${ }^{2,20,21}$ tends to reduce the aneurysm recurrence rate and the need for subsequent treatment. The
Neuroform stent may also promote progressive thrombosis ${ }^{2,20,22,23}$ and offers a scaffolding for reconstruction of the intimal layer of the parent artery at the aneurysm neck. In SENAT, progressive occlusion of UIAs was observed in 14\%, whereas previous Neuroform studies have demonstrated progressive occlusion rates ranging between $50 \%$ and $56.8 \% .^{2,7,11}$ However, what needs to be considered is the smaller aneurysm size in SENAT contributing to the higher initial occlusion rate. Subsequently, one may also explain the lower progressive thrombosis after stent placement in SENAT. This can also be explained by the distribution of aneurysms in this study. Complex anatomic location such as MCA bifurcation or paraophthalmic aneurysms accounted for $54.2 \%$ of cases and outnumbered more favorable sites. Otherwise, the final occlusion rate was similar to previous studies. ${ }^{5,9,17}$

The influence of initial packing attenuation for SAC also needs to be explored. Murayama et $\mathrm{al}^{19}$ demonstrated that recurrence rates of coiled aneurysms are highly dependent on neck size. In treated aneurysms ranging from $4-10 \mathrm{~mm}$ with a neck of $>4 \mathrm{~mm}$, the rate of recurrence reported was roughly $20 \%$. In comparison, in SENAT, the overall recurrence rate was $9.7 \%$ with a major recurrence rate of $4.3 \%$, requiring subsequent treatment. This recurrence rate is comparable with other Neuroform-assisted coiling studies. ${ }^{2,24,25}$ The SENAT retreatment rate is also comparable with the HELPS ${ }^{26}$ and Cerecyte $^{27}$ multicenter trials (3\% and $4 \%$, respectively) and is lower than previous studies such as the International Subarachnoid Aneurysm Trial ${ }^{28}$ and Matrix and Platinum Science-clinical trial ${ }^{29}$ (17\% and $10 \%$, respectively).

Some studies ${ }^{2,20,21,23}$ have suggested that stent placement improves the anatomic result, based on synergistic biologic, mechanic, and hemodynamic effects of the stent. ${ }^{2}$ The stent induces a tissue reaction and provides a matrix for endothelial growth leading to the formation of fibrous connective tissue over the stent struts. ${ }^{30}$ Coiling with the assistance of a stent, however, does not always result in denser packing compared with stand-alone coiling secondary to the lack of control of the kickback of the microcatheter. Nevertheless, the use of SAC may allow lower target VER. The mechanism of delayed occlusion with the Neuroform stent and coiling may be also attributed to a hemodynamic effect $^{31}$ via flow modification within the aneurysm. ${ }^{22,31}$ Indeed, the high porosity and the design of the struts of the Neuroform stent seem to promote an environment with a high oscillatory shear that thrombus formation prefers. ${ }^{31}$ Cantón et $\mathrm{al}^{22}$ showed that placing a Neuroform stent across the neck of a bifurcation aneu- 
rysm may reduce the magnitude of the velocity of the jet entering the sac by as much as $11 \%$. Therefore, one can consider that the stent's porosity may also be enhancing treatment durability. ${ }^{2}$

In SENAT, the overall periprocedural complication rate $(12.1 \%)$, which includes symptomatic and asymptomatic events, was in accordance with other previously published studies ${ }^{3,5-7,11,16}$ ranging from $9.4 \%-25 \%$. The occurrence of periprocedural thromboembolic events was low $(3.7 \%)$ and compares favorably with the literature $(4.5 \%-21 \%) .{ }^{5,8,32}$ As shown by Lessne et al, ${ }^{33}$ the thromboembolic rates for ruptured aneurysms and UIAs, treated by stent-assisted coiling, are very different (20\% and $3.1 \%$, respectively). This wide range could be explained by the lack of standardized antiplatelet regimen among centers. Recently, a case series of 284 patients harboring 302 aneurysms treated by stent-assisted coiling with the Neuroform stent reported an $8.8 \%$ incidence of ischemic strokes. $^{34}$

The delayed thromboembolic event rate in SENAT (3\%) is similar to previous studies ${ }^{5,11,25,33}$ ranging between $3.5 \%$ and $6.6 \%$. Among the 3 patients in SENAT, 1 case was concomitant to the cessation of dual antiplatelet therapy after stent placement. In the absence of firm current guidelines, the lack of a consolidated antiplatelet regimen did not permit a consensus on the length of antiplatelet therapy. Nevertheless, the reasonably low periprocedural and delayed thrombotic adverse event rate supports the use of double antiplatelet therapy for at least 2 months after treatment. Routine aggregometry tests are now available to assist in the identification and management of the varying response patients have to clopidogrel and aspirin. ${ }^{35}$

Permanent neurologic morbidity (1.9\%) and mortality (0\%) rates in the periprocedural period are low and are similar to previously reported Neuroform-assisted coiling series with a range of $2.9 \%$ and $11 \%$ for morbidity $3,11,16,17$ and $0 \%$ and $3.1 \%$ for mortality. ${ }^{3,6,16,17}$ In SENAT, the morbidity and mortality in the periprocedural period at 1 month $(0 \%$ and $0 \%)$ and at $12-18$ months ( $1 \%$ and $1 \%)$, were low and were comparable to the major coiling series of UIA in the literature. A recent meta-analysis published by Naggara et $\mathrm{al}^{36}$ showed a morbidity rate of $4.8 \%$ and a mortality rate of $1.2 \%$. In the International Study of Unruptured Intracranial Aneurysm, ${ }^{37}$ the morbidity rate was $9.1 \%$ and the mortality rate was $2 \%$. Major population-based studies ${ }^{38-42}$ regarding coiling of UIAs found morbidity rates ranging between $6.6 \%$ and $10.6 \%$ and mortality rates ranging between $0.4 \%$ and $1.7 \%$. Alshekhlee et $\mathrm{al}^{43}$ and Brinjikji et $\mathrm{al}^{44,45}$ recently reported lower rates of morbidity (3.6\% and $4.9 \%)$ and mortality ( $0.6 \%$ and $0.6 \%)$. Despite differing study designs and definitions of morbidity, SENAT demonstrated that the use of Neuroform in stent-assisted coiling of cerebral UIAs is acceptable and comparable.

The Neuroform is a self-expanding nitinol stent with a low radial force, and delayed in-stent stenosis is a well-recognized complication. Inflammation and cellular proliferation responses occur within 1 month after stent placement, followed by matrix production during the subsequent 5 months. ${ }^{46}$ These changes may explain delayed in-stent stenosis. In large series, ${ }^{23}$ most are asymptomatic. In SENAT, 3 cases (3\%) of in-stent stenosis were reported, but all were nonsignificant and clinically silent. This rate was slightly lower compared with the studies by Fiorella et $\mathrm{al}^{47}$ and Yoon and $\mathrm{Kim}^{48}$ (5.8\% and $7.8 \%$, respectively).

Regarding hemorrhagic complications, no intracranial hemorrhagic complication occurred, but 5 inguinal hematomas and 1 large retroperitoneal hematoma were reported. Nevertheless, dual antiplatelet therapy is mandatory, providing significantly greater inhibition of platelet activity. On the contrary, this dual therapy unavoidably increases the risk of bleeding. ${ }^{49}$

\section{CONCLUSIONS}

SENAT is the first prospective, consecutive, multicentric study on the Neuroform stent system. Stent-assisted coiling achieves high levels of occlusion with low rates of subsequent treatment compared with stand-alone coiling, despite a more difficult-to-treat population of patients with wide-neck aneurysms. SAC of UIA does not increase procedure-related morbidity and mortality rates. The rate of thromboembolic events was also similar compared with major stand-alone coiling studies.

\section{APPENDIX}

Centers and investigators participating in this study were the following: CHU Gui de Chauliac, Montpellier, France; Alain Bonafé, CHU La Pitié Salpêtrière, Paris, France; Alessandra Biondi, Nader Sourour, Betty Jean, CHU Lariboisière, Paris, France; Emmanuel Houdart, Jean-Pierre Saint Maurice, Fondation Rothschild, Paris, France; Jacques Moret, Laurent Spelle, Michel Piotin, Raphael Blanc, CHU Pellegrin, Bordeaux, France; Xavier Barreau, Jérôme Berge, CHU de la Côte de Nacre, Caen, France; Patrick Courthéoux, CHU Roger Salengro, Lille, France; Xavier Leclerc, CHU Dupuytren, Limoges, France; Charbel Mounayer, CHU G. \& R. Laënnec, Nantes, France; Hubert Desal, CHU Saint-Roch, Nice, France; Yves Chau, Jacques Sedat.

\section{ACKNOWLEDGMENTS}

The authors thank Marinette Moynier, PhD, for her assistance.

Disclosures: Alessandra Biondi-RELATED: Consulting Fee or Honorarium: France Stryker, Comments: I am PI of the SENAT study with Dr. A. Bonafé; UNRELATED: Consultancy: I am a consultant for Stryker. Alain Bonafé-RELATED: Consulting Fee or Honorarium: Stryker; Support for Travel to Meetings for the Study or Other Purposes: Stryker; UNRELATED: Consultancy: Stryker; Payment for Lectures (including service on speaker bureaus): Stryker. Vincent Costalat-UNRELATED: Travel/ Accommodations/Meeting Expenses Unrelated to Activities Listed: Stryker. Michel Piotin—UNRELATED: Consultancy: ARTEl, ${ }^{*}$ Comments: ARTEl is a nonlucrative association for the promotion of academic work in the field of neuroradiology; Payment for Development of Educational Presentations: ARTEI. ( ${ }^{\star}$ Money paid to institution.)

\section{REFERENCES}

1. Moret J, Cognard C, Weill A, et al. The "remodelling technique" in the treatment of wide neck intracranial aneurysms. Angiographic results and clinical follow-up in $\mathbf{5 6}$ cases. Interv Neuroradiol 1997;3:21-35

2. Kim DJ, Suh SH, Lee JW, et al. Influences of stents on the outcome of coil embolized intracranial aneurysms: comparison between a stent-remodeled and non-remodeled treatment. Acta Neurochir (Wien) 2010;152:423-29

3. Akpek S, Arat A, Morsi H, et al. Self-expandable stent-assisted coiling of wide-necked intracranial aneurysms: a single-center experience. AJNR Am J Neuroradiol 2005;26:1223-31

4. Alfke K, Straube T, Dorner L, et al. Treatment of intracranial broadneck aneurysms with a new self-expanding stent and coil embolization. AJNR Am J Neuroradiol 2004;25:584-91

5. Benitez RP, Silva MT, Klem J, et al. Endovascular occlusion of wide- 
necked aneurysms with a new intracranial microstent (Neuroform) and detachable coils. Neurosurgery 2004;54:1359-67; discussion 1368

6. Biondi A, Janardhan V, Katz JM, et al. Neuroform stent-assisted coil embolization of wide-neck intracranial aneurysms: strategies in stent deployment and midterm follow-up. Neurosurgery 2007;61: 460-68; discussion 468-69

7. Fiorella D, Albuquerque FC, Deshmukh VR, et al. Usefulness of the Neuroform stent for the treatment of cerebral aneurysms: results at initial (3-6-mo) follow-up. Neurosurgery 2005;56:1191-201; discussion 1201-02

8. Fiorella D, Albuquerque FC, Han P, et al. Preliminary experience using the Neuroform stent for the treatment of cerebral aneurysms. Neurosurgery 2004;54:6-16; discussion 16-17

9. Howington JU, Hanel RA, Harrigan MR, et al. The Neuroform stent, the first microcatheter-delivered stent for use in the intracranial circulation. Neurosurgery 2004;54:2-5

10. Liang G, Gao X, Li Z, et al. Neuroform stent-assisted coiling of intracranial aneurysms: a 5 year single-center experience and followup. Neurol Res 2010;32:721-27

11. Maldonado IL, Machi P, Costalat V, et al. Neuroform stent-assisted coiling of unruptured intracranial aneurysms: short- and midterm results from a single-center experience with 68 patients. AJNR Am J Neuroradiol 2011;32:131-36

12. Wajnberg E, de Souza JM, Marchiori E, et al. Single-center experience with the Neuroform stent for endovascular treatment of widenecked intracranial aneurysms. Surg Neurol 2009;72:612-19

13. Wanke I, Doerfler A, Schoch B, et al. Treatment of wide-necked intracranial aneurysms with a self-expanding stent system: initial clinical experience. AJNR Am J Neuroradiol 2003;24:1192-99

14. Raymond J, Guilbert F, Weill A, et al. Long-term angiographic recurrences after selective endovascular treatment of aneurysms with detachable coils. Stroke 2003;34:1398-403

15. Gao X, Liang G, Li Z, et al. Complications and adverse events associated with Neuroform stent-assisted coiling of wide-neck intracranial aneurysms. Neurol Res 2011;33:841-52

16. Gao X, Liang G, Li Y, et al. Neuroform stent-assisted coiling of large and giant intracranial aneurysms: angiographic and clinical outcomes in 71 consecutive patients. Neurol India 2010;58:825-32

17. Raslan AM, Oztaskin M, Thompson EM, et al. Neuroform stentassisted embolization of incidental anterior communicating artery aneurysms: long-term clinical and angiographic follow-up. Neurosurgery 2011;69:27-37; discussion 37

18. Jabbour P, Koebbe C, Veznedaroglu E, et al. Stent-assisted coil placement for unruptured cerebral aneurysms. Neurosurg Focus 2004; 17:E10

19. Murayama Y, Nien YL, Duckwiler G, et al. Guglielmi detachable coil embolization of cerebral aneurysms: 11 years' experience. J Neurosurg 2003;98:959-66

20. Piotin M, Blanc R, Spelle L, et al. Stent-assisted coiling of intracranial aneurysms: clinical and angiographic results in 216 consecutive aneurysms. Stroke 2010;41:110-15

21. Yahia AM, Latorre JG, Gordon V, et al. Progressive occlusion of aneurysms in Neuroform stent-assisted treatment of intracranial aneurysms. J Neurol Neurosurg Psychiatry 2011;82:278-82

22. Cantón G, Levy DI, Lasheras JC. Hemodynamic changes due to stent placement in bifurcating intracranial aneurysms. J Neurosurg 2005;103:146-55

23. Lubicz B, Bandeira A, Bruneau M, et al. Stenting is improving and stabilizing anatomical results of coiled intracranial aneurysms. Neuroradiology 2009;51:419-25

24. Sedat J, Chau Y, Mondot L, et al. Endovascular occlusion of intracranial wide-necked aneurysms with stenting (Neuroform) and coiling: mid-term and long-term results. Neuroradiology 2009;51: 401-09

25. Yahia AM, Gordon V, Whapham J, et al. Complications of Neuroform stent in endovascular treatment of intracranial aneurysms. Neurocrit Care 2008;8:19-30

26. White PM, Lewis SC, Gholkar A, et al. Hydrogel-coated coils versus bare platinum coils for the endovascular treatment of intracranial aneurysms (HELPS): a randomised controlled trial. Lancet 2011;377:1655-62

27. Coley S, Sneade M, Clarke A, et al. Cerecyte coil trial: procedural safety and clinical outcomes in patients with ruptured and unruptured intracranial aneurysms. AJNR Am J Neuroradiol 2012;33:474-80

28. Molyneux A, Kerr R, Stratton I, et al. International Subarachnoid Aneurysm Trial (ISAT) of neurosurgical clipping versus endovas- cular coiling in 2143 patients with ruptured intracranial aneurysms: a randomised trial. Lancet 2002;360:1267-74

29. Johnston SC, McDougall CG, Gholkar A. On behalf of MAPS Steering Committee and Investigators: the MAPS trial-Matrix and Platinum Science-clinical trials. Paper presented at: 8th Annual Meeting of the Society of Neurointerventional Surgery, Colorado Springs, Colorado; July 25-28, 2011

30. Geremia G, Brack T, Brennecke L, et al. Occlusion of experimentally created fusiform aneurysms with porous metallic stents. AJNR Am J Neuroradiol 2000;21:739-45

31. Jou LD, Mawad ME. Hemodynamic effect of Neuroform stent on intimal hyperplasia and thrombus formation in a carotid aneurysm. Med Eng Phys 2011;33:573-80

32. Yahia AM, Latorre J, Gordon V, et al. Thromboembolic events associated with Neuroform stent in endovascular treatment of intracranial aneurysms. J Neuroimaging 2010;20:113-17

33. Lessne ML, Shah P, Alexander MJ, et al. Thromboembolic complications after Neuroform stent-assisted treatment of cerebral aneurysms: the Duke Cerebrovascular Center experience in 235 patients with 274 stents. Neurosurgery 2011;69:369-75

34. Fiorella D, Albuquerque FC, Woo H, et al. Neuroform stent assisted aneurysm treatment: evolving treatment strategies, complications and results of long term follow-up. J Neurointerv Surg 2010;2:16-22

35. Lee DH, Arat A, Morsi $\mathrm{H}$, et al. Dual antiplatelet therapy monitoring for neurointerventional procedures using a point-of-care platelet function test: a single-center experience. AJNR Am J Neuroradiol 2008;29:1389-94

36. Naggara ON, White PM, Guilbert F, et al. Endovascular treatment of intracranial unruptured aneurysms: systematic review and metaanalysis of the literature on safety and efficacy. Radiology 2010; 256:887-97

37. Wiebers DO, Whisnant JP, Huston J, et al. Unruptured intracranial aneurysms: natural history, clinical outcome, and risks of surgical and endovascular treatment. Lancet 2003;362:103-10

38. Johnston SC, Dudley RA, Gress DR, et al. Surgical and endovascular treatment of unruptured cerebral aneurysms at university hospitals. Neurology 1999;52:1799-805

39. Johnston SC, Zhao S, Dudley RA, et al. Treatment of unruptured cerebral aneurysms in California. Stroke 2001;32:597-605

40. Hoh BL, Rabinov JD, Pryor JC, et al. In-hospital morbidity and mortality after endovascular treatment of unruptured intracranial aneurysms in the United States, 1996-2000: effect of hospital and physician volume. AJNR Am J Neuroradiol 2003;24:1409-20

41. Barker FG, Amin-Hanjani S, Butler WE, et al. In-hospital mortality and morbidity after surgical treatment of unruptured intracranial aneurysms in the United States, 1996-2000: the effect of hospital and surgeon volume. Neurosurgery 2003;52:995-1007; discussion 1007-09

42. Higashida RT, Lahue BJ, Torbey MT, et al. Treatment of unruptured intracranial aneurysms: a nationwide assessment of effectiveness. AJNR Am J Neuroradiol 2007;28:146-51

43. Alshekhlee A, Mehta S, Edgell RC, et al. Hospital mortality and complications of electively clipped or coiled unruptured intracranial aneurysm. Stroke 2010;41:1471-76

44. Brinjikji W, Rabinstein AA, Lanzino G, et al. Patient outcomes are better for unruptured cerebral aneurysms treated at centers that preferentially treat with endovascular coiling: a study of the $\mathrm{Na}$ tional Inpatient Sample 2001-2007. AJNR Am J Neuroradiol 2011;32:1065-70

45. Brinjikji W, Rabinstein AA, Lanzino G, et al. Effect of age on outcomes of treatment of unruptured cerebral aneurysms: a study of the National Inpatient Sample 2001-2008. Stroke 2011;42:1320-24

46. Nikol S, Huehns TY, Hofling B. Molecular biology and post-angioplasty restenosis. Atherosclerosis 1996;123:17-31

47. Fiorella D, Albuquerque FC, Woo H, et al. Neuroform in-stent stenosis: incidence, natural history, and treatment strategies. $\mathrm{Neu}$ rosurgery 2006;59:34-42; discussion 34-42

48. Yoon KW, Kim YJ. In-stent stenosis of stent assisted endovascular treatment on intracranial complex aneurysms. J Korean Neurosurg Soc 2010;48:485-89

49. Serebruany VL, Malinin AI, Ziai W, et al. Effects of clopidogrel and aspirin in combination versus aspirin alone on platelet activation and major receptor expression in patients after recent ischemic stroke: for the Plavix Use for Treatment of Stroke (PLUTO-Stroke) trial. Stroke 2005;36:2289-92 